\title{
Health Hazards In Prosthodontic Practice - A Review
}

\author{
U. Krishna Kumar', Sanjay Murgod ${ }^{2}$, Beena Roopak ${ }^{3}$ \\ ${ }^{1}$ Department of Prosthodontics including Crown and bridge and Implantology, Rajarajeshwari Dental College and Hospital, Bengaluru, \\ Karnataka, India, ${ }^{2}$ Department of Oral Pathology and Microbiology, Rajarajeshwari Dental College and Hospital, Bengaluru, \\ Karnataka, India, ${ }^{3}$ Department of Oral Maxillofacial Surgery, Rajarajeshwari Dental College and Hospital, Bengaluru, Karnataka, \\ India
}

Email for correspondence: ukrishnav@gmail.com

\begin{abstract}
The intent of the present article is to analyze the potential hazards and risks involved in persons exposed to prosthodontic practice. These risks include exposure to physical and chemical hazards, dental materials, infectious environment, inappropriate working pattern, and psychosocial stress. The potential harm of these hazards and its prevention is highlighted. Prosthodontists, students, dental technicians, and others working in the prosthodontic clinics and laboratory should be aware of the specific risk factors and take measures to prevent and overcome these hazards.
\end{abstract}

Key words: Biohazards, health hazards, occupational hazards

\section{INTRODUCTION}

Occupational hazards can be defined as a risk accepted as a consequence of a particular occupation to a person usually arising out of employment. As related to prosthodontic practice, it can also refer to a clinical or laboartory dental materials, substance, process, or situation that predisposes or itself causes accidents or diseases. Prosthodontist and related auxiliary employees are usually exposed to a number of occupational hazards, and it requires contact with restorative and prosthetic dental materials of widely varied composition such as metals, resin-based synthetic polymers, and dental ceramics. The nature of prosthetic practice is such that much of the work needs outsourcing from the clinic to the laboratories, thereby widening the circle of potentially infectious agents. ${ }^{[1]}$ In routine prosthodontic practice, potential health risk may be due to various factors, and they are as follows.

\begin{tabular}{|l|l|}
\hline Quick Response Code & Article Info: \\
\hline doi: 10.5866/2018.10.10030 & $\begin{array}{l}\text { Received: } 28-12-2017 \\
\text { Revised: } 22-01-2018 \\
\text { Accepted: 06-02-2018 } \\
\text { Available Online: } 15-04-2018,2018 \text { (www. } \\
\text { nacd.in)( NAD, } 2017 \text { - All rights reserved }\end{array}$ \\
\hline
\end{tabular}

\section{Physical hazards}

Physical hazards associated with prosthodontic practice include direct physical, thermal, acoustic, and visionary damage and various problems associated with bad ergonomics. Direct physical trauma includes accidental skin cuts and abrasion which is mostly due to the misuse of instruments and equipment, and this kind of trauma can act as a portal entry for infections or toxic materials. According to a study, prosthodontist has the second highest prevalence rate of 5\% annually for the percutaneous injuries. ${ }^{[2]}$ The second most common injury in a prosthodontic clinic or laboratory is burns from Bunsen burners, spirit lamps, blow torches, careless handling of hot instruments, wax splashes, spontaneous ignitions of inflammable materials, and use of solders and molten metals. ${ }^{[3]}$ This type of injury can be minimized by the use of flameproof material by the provision of accessible and appropriate fire extinguishers and regular practice of routine fire drill. NFPA 101-Life Safety Code is the most widely used source to shield people based on building construction, protection, and occupancy features that minimize the effects of fire and related hazards. The title of the NFPA 101-Life Safety Code was changed from building exit code to code for safety to life from fire in buildings. 2010 
Oregon Fire Code also gives guidelines in the same manner as NFPA 101-Life Safety Code does.

The fire protection guide should include components like responsibility of various sections in the event of fire,procedures and protocols for mock drills,establishment of fire combating and evacuation teams,electrical security and systems,regular maintenance and inspection of that area should be advisable. Quantity of inflammable and combustible liquids located outside of storage cabinets should be constrained to barely single day supply and management of such materials should be done by authorized persons only. A large quantity of these items should be stored as per applicable regulations and protective methods. Large storage space areas should have a fire fortification system established.

The fire protection guides have following components - preparation for fire prevention and management, maintenance agenda for scheme linked to fire prevention and control, and examination procedure for fire safety installations, and codes for declaration area should be advisable. At least one fire extinguisher should be installed in the storage section. The effects of vibration on the hand can also result in vibration syndrome or vibration white finger entity where symptoms of main effects are narrowing of arteries in fingers and hands and damage to the ends of the nerves. Early symptoms include reduced blood circulation in the fingers, reduced sensitivity of the fingers to pain, touch, vibration, and temperature, and blanching of one or more fingertips. Damage to hand fingers; nails also occur due to improper handling of casts during trimming procedures.

\section{Visionary hazards}

Eye injury is another associated hazard that has been attributed to the use of high-speed cutting tools. The effect can range from mild irritation through corneal abrasion and ulceration to complete blindness. ${ }^{[4]}$ Common causes include use of high speed of rotary instruments which generates the sprinklers which are very hot, sharp, and infected. ${ }^{[5]}$ Painful reactions are elicited when materials such as monomer and spirit are accidently splashed into the eye. Pumice containing lime or quartz can also lead to pain and corneal abrasion. Blue curing light used for polymerization of restorative resin material ranges from 400 to $500 \mathrm{~nm}$ wavelengths which is associated with corneal damage and abrasion. The effect of blue light can be cumulative or acute depending on its nature and duration of use. ${ }^{[6,7]}$ Exposure to blue light usually leads to acute injuries. According to a report, there is increase in ocular injury risk at $440 \mathrm{~nm}$ of wavelength. Possible precautions which can be taken to protect our self are the use of protective glasses, goggles, and loupes. When the blue light strikes the retina, they inhibit the formation of cytochrome-C-oxidase which transports oxygen to photoreceptors and other retinal cells, and thereby degeneration of retina occurs. ${ }^{[8]}$ When lasers are used to treat fixed partial dentate patients. wearing glasses is mandatory.

\section{Acoustic hazards}

Prosthodontics had always been an occupational interest in the subject of noise-induced hearing loss; this is due to the use of high-speed turbine dental drills used during surgeries, and also use of ultrasonic instruments, high velocity suctions, cleaners, and model trimmers during routine laboratory procedures. ${ }^{[9]}$ Sound emitted ranging from $66 \mathrm{db}$ to $91 \mathrm{db}$ was found to damage the hearing. It is estimated that sound energy contribution of a typical prosthodontic practice is about $8 \%$ of dentist's average $24 \mathrm{~h}$ noise exposure. ${ }^{[10]}$ Loss of hearing and tinnitus are the common side effect of noise beyond the permissible levels in a setup. Risk depends on the susceptibility of a particular individual, total daily exposure, and type of instruments used. Ear protection should be worn during the procedures and hearing test at least once a year should be recommended.

\section{Chemical hazards}

Resins enter the body in vapor form during inhalation or from direct contact through the skin. Resin vapor in the air at the level of more than $125 \mathrm{ppm}$ may cause teary eyes, sore throat, and coughing. ${ }^{[11,12]}$ Direct skin contact can cause itching, burning, redness, swelling, and cracking of the skin. Prolong skin contact with resins may cause tingling, numbness, or whitening of the fingers. Resins can easily penetrate clothing and even surgical gloves. ${ }^{[13]}$ Overexposure to resins can injure our brain, and symptoms include headache, drowsiness, nausea, weakness, fatigue, irritability, and dizziness. Universally legal exposure limits to have adopted a permissible limit for the amount of resins that is 100 parts of resins per million parts of air which is equal to $400 \mathrm{mg}$ of resins per cubic meter of air. Average exposure for any $8 \mathrm{~h}$ work shift is 100 ppm or less. ${ }^{[14,15]}$ 
Methods to reduce the resin exposure are as follows: (1) Replacement with a safer chemical, (2) infrastructural controls at the workplace, and (3) personal protective equipment. Even the most resistant materials will be penetrated quickly, so gloves should be replaced immediately. Metal alloys pose hazards to dentist and technicians during casting and finishing of the metal restoration and frameworks. Two of the most common constituents for these alloys are nickel and chromium which are known to be potential carcinogens. Nickel is associated with nasal cancer and chromium with lung cancer in workers exposed to these metals. ${ }^{[16]}$ Both of these metals can provoke skin irritation sensitization or hypersensitivity reactions. A study reported that 53 of 70 dental technicians were affected by pneumoconiosis which could be due to dust from the processing of these dental materials. ${ }^{[17]}$ Beryllium exposure to its particle or fumes is associated with contact dermatitis and chronic granulomatous lung disease called as chronic beryllium disease. ${ }^{[18,19]}$ The risk is greater during casting process in the absence of adequate exhaust and filtrations system.

Skin irritation and dermatitis can be induced by prolonged handling of some materials such as paraffin, bee, and carnauba wax. Ceramic materials are generally considered as inert, but dust from these materials during handling, manipulating, and finishing the restoration represent a potential problem for laboratory and clinical personnel. Inhalation of these particles may lead to silicosis. Irreversible hydrocolloids consist of about $60 \%$ of diatomaceous earth, and these particles of $<3 \mu \mathrm{m}$ in diameter and $>20 \mu \mathrm{m}$ in length can be inhaled while manipulation and may prove to be carcinogenic over a long time span. Hence, dust-free and lead-free alginate materials should be used ${ }^{[20]}$ Electroplating solutions such as potassium cyanide and silver cyanide are commonly used for electroplating of elastomeric impression materials. Cyanide is known harmful agent to the body and if it comes in contact with acids by any chance will lead to the production of hydrogen cyanide gas which is potentially lethal.

These solutions should be kept away from all acids, and if avoidable, silver plating of impressions should be discouraged. Latex gloves dusted with cornstarch powder are more often used in dental practice. Corn starch is allergenic and gives immediate allergic reactions. Natural latex, synthetic rubber, and synthetic polymeric glove materials showed various degrees of cytotoxicity, and in the present-day practice silicone, a powderfree glove which has less risk is used to avoid allergic reactions. Eugenol is one of the most cytotoxic and allergic substances known which should be used carefully in dentistry. Various studies of pulp sensitivity following cementation with zinc phosphate and glass ionomer cements showed less sensitivity to zinc phosphate than glass ionomer during the first 2 weeks, but after 3 months, there are no differences. Modern resin-based luting cements are also well tolerated to pulp.

\section{Microbial hazards}

Bacterial contamination from spatter and aerosol dissemination generated at high-speed instrumentation remains as a significant risk to dental personnel's and the composition of the aerosol produced is also of great concern. The size of particles ranges between 2 and $30 \mu \mathrm{m}$ and can lead to many respiratory ailments as they can reach to alveoli. The common entry point of infection for a dentist includes epidermis of hand, oral and nasal epithelium conjunctiva, and epithelium of respiratory tract including trachea, bronchus, and alveoli. Contaminated impressions are another common site of infection in prosthodontic practice. Impression material acts as a vehicle for the transfer of both pathogenic bacteria and virus and causes cross-contamination in the clinic and the laboratory. Dental impressions and casts can be effectively disinfected by the use of liquid or gaseous chemicals. Other possible sources of infectious contamination are dental unit waterlines, handpieces, saliva ejectors, suction tubes, airotors, and radiological instruments. Dental unit waterlines pose as a threat as it may harbor opportunistic and respiratory pathogens such Mycobacterium species and Pseudomonas species.

\section{Ergonomic hazards}

Ergonomic hazards constitute a physical factor within the environment that harms the musculoskeletal system. Common symptoms are the presence of discomfort, disability, or persistent pain in joints, muscles, tendons, and other soft tissues. Prosthodontists are at high risk of neck and back problem due to work ergonomic restriction associated with oral cavity. These working restrictions cause them to assume stressful body positions to achieve good access and period of time which in turn lead to symptoms such as low back pain, stiffness, tingling sensation and paresthesia, and muscle weakness. 
Repetitive and forceful use of vibrating tools increases the fluid accumulation and inflammation. This can be minimized by at least 6 min of rest from work every hour, proper ergonomic dental unit design, personalized rehabilitation exercises, regular stretching, and aerobic activities. ${ }^{[21-24]}$ Tendinopathies and carpal tunnel syndrome were associated with both repetitive work and forceful work. The hand performs many complex tasks, and the tendons move inside tendon sheaths with synovial fluid. Symptoms can appear from any activity causing prolonged increase in passive or active pressure in the carpal canal. According to various studies, nearly $50 \%$ of carpal tunnel syndrome subjects in the general population were work-related. The use of improper gloves results in excessive tension on thenar eminence.

\section{Sociopsycological hazards}

Prosthodontist encounters numerous sources of professional stress, beginning in the dental clinic. Important risk factors contributing to stress among dentists are coping with difficult or uncooperative patients, over workload, constant drive for technical perfection, underuse of skills, challenging environment,and low self-esteem. Various physical and emotional demands result in physical and mental burnout. Stress management workshops, deep breathing exercises, relaxation, hypnosis, and desensitization techniques help to manage these psychosocial hazards. These physical and emotional demands result in physical and mental burnout. A comparison of stress levels and coping stress in male and female dentists showed that stress levels were similar, although women experienced more personal and domestic stress. ${ }^{[25]}$ Regarding coping response, both the sexes exhibited similarity in most respects, except that women were more inclined to discuss their problems.

\section{CONCLUSION}

The nature of prosthetic practice is such that it has a wide circle of biocontact of potentially harmful agents and physical trauma, thereby increasing the susceptibility to a number of occupational hazards. ${ }^{[26-28]}$ It is the responsibility of prosthodontist and prosthodontic-related technicians and auxillaries to understand the specific risks or hazard agents and formulate an effective management protocols. Understanding the various risks will educate the professional for a better work practice and care of personal health. A mere knowledge of such hazard and familiarity with its characteristics is not sufficient for an individual to assess the potential threat. Although a dental clinic will probably never be free of these dangers and threat, necessary measures should be taken to eliminate them as much as possible. Furthermore, it is ones' responsibility to report the biological side effects associated with the use of various dental materials to certifying bodies or health authorities so that reliable research can be done to clarify various safety issues and frequency of adverse reactions with the use of these materials in general dentistry including prosthodontic treatment.

\section{REFERENCES}

1. Tillberg A, Jarvholm B, Berglund A. Risks with dental materials. Dent Mater 2008;24:940-3.

2. Jacobsen N, Aasenden R, Pettersen AH. Occupational health complaints and adverse patient reactions as perceived by personnel in public dentistry. Community Dent Oral Epidemiol 1991;19:155-9.

3. Siew C, Chang SB, Gruninger SE, Verrusio AC, Neidle EA. Self-reported percutaneous injuries in dentists: Implications for HBV, HIV, transmission risk. J Am Dent Assoc 1992;123:36-44.

4. Szymanska J. Dentist's hand symptoms and high-frequency vibration. Ann Agric Environ Med 2001;8:7-10

5. Farrier SL, Farrier JN, Gilmour AS. Eye safety in operative dentistry - A study in general dental practice. Br Dent J 2006;200:218-23.

6. Scully C, Cawson RA, Griffiths MJ. Mortality and some aspects of morbidity: Ch.1. In: Occupational hazard to dental staff. BMJ 1990;2:1-21.

7. Gasyna EM, Rezaei KA, Mieler WF. Blue light induces apoptosis in human fetal retinal pigment epithelium. Invest Ophthalmol Vis Sci 2006;47:180.

8. Roll EM, Jacobsen N, Hensten-Pettersen A. Health hazards associated with curing light in the dental clinic. Clin Oral Investig 2004;8:113-7.

9. Work Related Hearing Loss. NIOSH Publication Number 2001-103. Centers for Disease Control and Prevention; 2012.

10. Szymanska J. Work-related noise hazards in the dental surgery. Ann Agric Environ Med 2000;7:67-70.

11. Pettersen AH, Jacobsen N. Perceived side effects of biomaterials in prosthetic dentistry. J Prosthet Dent 1991;65:138-44

12. Haberman AL, Pratt M, Storrs FJ. Contact dermatitis from beryllium in dental alloys. Contact Dermatitis 1993;28:157-62.

13. Kim TS, Kim HA, Heo Y, Park Y, Park CY, Roh YM, et al Level of silica in the respirable dust inhaled by dental technicians with demonstration of respirable symptoms. Ind Health 2002;40:260-5. 
14. Choudat D. Occupational lung diseases among dental technicians. Tuber Lung Dis 1994;75:99-104.

15. Woody RD, Huget EF, Cutright DE. Characterization of airborne particles from irreversible hydrocolloids. J Am Dent Assoc 1977;94:501-4.

16. Roberta T, Federico M, Federica B, Antonietta CM, Sergio B, Ugo C, et al. Study of the potential cytotoxicity of dental impression materials. Toxicol In Vitro 2003;17:657-62.

17. Turjanmaa K, Alenius H, Kiljunen SM, Reunala T, Palosuo T. Natural rubber latex allergy. Allergy 1996;51:593-602.

18. Bentley CD, Burkhart NW, Crawford JJ. Evaluating spatter and aerosol contamination during dental procedures. J Am Dent Assoc 1994;125:579-84.

19. Jennings KJ, Samaranayake LP. The persistence of microorganisms on impression materials following disinfection. Int J Prosthodont 1991;4:382-7.

20. McNeill MR, Coulter WA, Hussey DL. Disinfection of irreversible hydrocolloid impressions: A comparative study. Int J Prosthodont 1992;5:563-7.

21. Alexopoulos EC, Stathi IC, Charizani F. Prevalence of musculoskeletal disorders in dentists. BMC Musculoskelet Disord 2004;5:16.
22. Milerad E, Ericson MO, Nisell R, Kilbom A. An electromyographic study of dental work. Ergonomics 1991;34:953-62.

23. Fish DR, Morris-Allen DM. Musculoskeletal disorders in dentists NY State. Dent J 1998;64:44-8.

24. Kay EJ, Lowe JC. A survey of stress levels, self-perceived health and health-related behaviours of UK dental practitioners in 2005. Br Dent J 2008;204:E19.

25. Rankin JA, Harris MB. Comparison of stress and coping in male and female dentists. J Dent Pract Adm 1990;7:166-72

26. Chugh A. Occupational hazards in Prosthetic dentistry Dentistry 2017;7:410.

27. Atlas RM, Williams JF, Huntington MK. Legionella contamination of dental unit waters. Appl Environ Microbiol 1995;61:1208-13.

28. Harutunian K, Gargallo-Albiol J, Figueiredo $\mathrm{R}$, Gay-Escoda C. Ergonomics and musculoskeletal pain among postgraduate students and faculty members of the School of dentistry of the university of Barcelona (Spain). A cross-sectional study. Med Oral Patol Oral Cir Bucal 2011;16:425-42. 